\title{
HERMENÊUTICA FILOSÓFICA: O CONCEITO DE EXPERIÊNCIA COMO CONTRIBUIÇÃO PARA O FORTALECIMENTO DA EDUCAÇÃO AMBIENTAL
}

Rodrigo Eder Zambam¹; Humberto Calloni²

\section{RESUMO}

A fim de que possamos compreender minimamente a influência que a ciência moderna possui na crise socioambiental, objetivamos problematizar o conceito de "experiência" como base do projeto moderno de conhecimento e sua influência na educação tradicional. Em outra entrada, com a Hermenêutica Filosófica de Hans-Georg Gadamer (1900-2002), propomos pensar a "experiência" em seu sentido verdadeiro, ou seja, com sua característica "negativa": "aquela na qual o homem se torna consciente de sua finitude". Propomos que a mesma se dê no "jogo dialógico" como possibilidade da Educação acontecer de forma coletiva.

Palavras-chave: Diálogo; Educação Ambiental; Experiência.

\section{PHILOSOPHICAL HERMENEUTICS: THE CONCEPT OF EXPERIENCE AS A CONTRIBUTION TO THE STRENGTHENING OF ENVIRONMENTAL EDUCATION}

\begin{abstract}
In order to understand the influence of modern science on the socioenvironmental crisis, we aim to problematize the concept of "experience" as the basis of the modern knowledge project and its influence on traditional education. In another entry, with the Philosophical Hermeneutics of Hans-Georg Gadamer (1900-2002), we propose to think of "experience" in its true sense, that is, with its "negative" characteristic: "that in which man becomes conscious of its own finitude. " We propose that the experience should be in terms of a "dialogical game" as a possibility for Education to happen in a collectively way.
\end{abstract}

Keywords: Dialogue; Environmental Education; Experience.

\section{Introdução}

\footnotetext{
1 Mestre em Filosofia. Professor de Filosofia da Universidade Federal do Rio Grande - FURG. Doutorando em Educação Ambiental - PPGEA/FURG. E-mail: rodrigozambam@gmail.com. 2 Doutor em Educação. Professor titular da Universidade Federal do Rio Grande - FURG. Líder do Grupo de Estudo e Pesquisa da Complexidade GEC/FURG/CNPq. E-mail: hcalloni@mikrus.com.br.
} 
O presente é tão grande, não nos afastemos.

Não nos afastemos muito, vamos de mãos dadas.

(Mãos dadas - Carlos Drummond de Andrade)

Debater a crise socioambiental que é fruto de uma postura antropocêntrica atroz, do racionalismo instrumental que é base das ações do homem moderno, coloca-se como condição necessária para pensarmos soluções que busquem alternativas fora das relações míopes e da postura objetivante presente em nossa sociedade. $\mathrm{O} X$ Encontro e Diálogos com a Educação Ambiental (EDEA) lança o seguinte problema: "Como ser coletivo em tempos de retrocesso?" Ou seja, em uma sociedade que valoriza e reproduz ações individualista, como pensarmos ações que vão de encontro aos princípios teóricos e as ações que devastam o coletivo? Os fundamentos da Educação Ambiental (EA) apresentam-se como condição sine qua non na estruturação de conceitos que auxiliam na reflexão como possibilidade de mudança. A possibilidade para enfrentarmos tamanho desafio frente à violência desenfreada que invade nossa sociedade, é termos na Educação sustentação teórica para que esta se torne ambiental. Que desempenhe seu papel social de reflexão e crítica dos valores impostos pelo sistema atual fazendo do debate ético um dos pilares para se pensar em relações coletivas contrapondo o radicalismo individual.

Diante do desafio da coletividade em tempos de retrocesso, a proposta do presente artigo é incursionarmos pelos fundamentos da Educação Ambiental guiados pela proposta da Hermenêutica Filosófica de Hans-Georg Gadamer (1900-2002) como possibilidade de uma Educação que ultrapasse as restrições teóricas e metodológicas presentes na Educação Tradicional. Para tal desafio, propomos problematizar o conceito de "experiência" presente nas ciências positivas como base da dinâmica moderna de conhecimento em contraponto ao conceito de experiência presente na proposta da hermenêutica filosófica. O primeiro conceito é base do projeto moderno que tem no "método" o caminho para um conhecimento com resultados seguros. Esta proposta influencia a Filosofia e a Educação almejando nestas também a noção de certeza como condição de verdade; a segunda concepção busca romper com a dinâmica da modernidade colocando o conhecimento como um acontecimento a partir da proposta dialógica. 
Por questões didáticas, o texto será dividido em três momentos. No primeiro, apresentaremos os conceitos referentes à experiência a partir da proposta moderna. Traremos alguns conceitos que Gadamer apresenta em sua complexa obra e que auxilia na compreensão do rasgo conceitual ocorrido com sua teoria. No segundo momento apresentaremos a compreensão de experiência na esteira da hermenêutica filosófica. Em outras palavras: alguns conceitos que auxiliam para o entendimento da proposta filosófica de sua hermenêutica. Como encerramento colocaremos algumas proposições que possam auxiliar os fundamentos da Educação Ambiental orientados pela hermenêutica filosófica como possibilidade de uma Educação que pense a coletividade em oposição aos desmontes causados pela propagação do individualismo que impera em nossa sociedade.

\section{A experiência na ciência}

Nas trilhas do pensamento gadameriano e buscando elementos para a fundamentação da Educação Ambiental, o conceito de "experiência" se coloca como centro da hermenêutica filosófica. Vamos tratá-lo, nesse momento, de forma separada por uma questão puramente didática. Porém, ao lermos com atenção a extensa obra de Gadamer, a experiência ontológica, enquanto hermenêutica, está presente no todo de sua obra. Conceitos como: diálogo hermenêutico, jogo, história efetual, finitude etc, são marcados pela experiência enquanto acontecer hermenêutico. "O que precisamos reter para a análise da consciência da história efetual é exatamente isso: ela tem a estrutura da experiência" (GADAMER, 2004a, p. 352³). É que a nossa condição de seres históricos é marcada pela experiência enquanto acontecimento de nossa finitude. Não há como estudarmos a hermenêutica filosófica sem termos como pano de fundo a experiência como conceito chave de sua teoria. Faz-se necessário uma diferenciação entre a experiência das ciências positivas e a experiência pensada enquanto ontológica primordial. Gadamer nos alerta para a mutilação, ou seja, pelo descaso feito pelas ciências positivas a partir de seu método indutivo que retira a função original da experiência. "Uma vez que a lógica da indução desempenha uma função decisiva para as ciências da

\footnotetext{
${ }^{3}$ A paginação está de acordo com a obra original "Wahrheit und Methode".
} 
natureza, esse conceito viu-se submetido a uma esquematização epistemológica que me parece mutilar grandemente seu conteúdo originário" (lbidem, p. 352).

O que o filósofo coloca, ao introduzir esse assunto de forma mais pontual, é que a experiência realizada pela ciência não é a experiência pensada por ele para a hermenêutica filosófica. Qual o principal motivo? O fato de a ciência não ver na experiência os elementos históricos, isto é, a nossa condição de seres pertencentes a uma condição histórica. A experiência da ciência se estabelece na capacidade metodológica de repetir novamente a mesma experiência. Esta é a base do indutivismo moderno na busca pelo conhecimento universal. Para a ciência, esse conhecimento tem que estar liberto da experiência da historicidade. Ela não tem qualquer serventia, ao contrário, traz apenas entraves para a conquista de um conhecimento metodologicamente fundamentado e livre de preconceitos.

\begin{abstract}
O objetivo da ciência é tornar a experiência tão objetiva a ponto de anular nela qualquer elemento histórico. No experimento das ciências naturais isso é alcançado através de seu aparato metodológico. Algo parecido se dá também por meio do método da crítica histórica no âmbito das ciências do espírito. Em ambos os casos a objetividade é garantida pelo fato de as experiências feitas ali poderem ser repetidas por qualquer pessoa. Assim como na ciência da natureza os experimentos devem ser passíveis de verificação, também nas ciências do espírito o procedimento completo deve ser passível de controle. Nesse sentido, na ciência não pode restar espaço para a historicidade da experiência. (GADAMER, 2004a, p. 352).
\end{abstract}

Na citação acima, Gadamer destaca que a objetividade se apresenta tanto nas ciências naturais (que é algo mais próximo de quem estuda a Educação Ambiental, com todas as críticas feitas ao conceito de ciência moderna) como também se encontra nas ciências do espírito, ou seja: percebemos a influência do método que visa a objetividade ao exigir o controle dos procedimentos e dos resultados. Se o controle se coloca como pano de fundo dos procedimentos científicos, o que extrapola a objetividade estrá descartado. Logo, a historicidade da experiência, que apresenta a finitude, os limites do ser humano, ou seja, a verdadeira experiência enquanto existencialidade, não tem valor para a ciência. "Na ciência, à experiência da historicidade é, então, negado qualquer significado. A ciência não vê qualquer utilidade na experiência da historicidade. Em vez disso, a experiência só é 
válida quando puder ser repetida ad infinitum" (GRÜN, 2007, p. 139). Pensar a experiência para a ciência tem 0 destaque na possibilidade de repetir a experiência; é como se esta fosse sempre a mesma; repete-se o procedimento com a segurança do resultado já ser conhecido de antemão.

Sob as lentes do método científico, o verdadeiro conhecimento se baseia na capacidade da repetição do mesmo procedimento. Isto está muito bem representado nos procedimentos desenvolvidos pela ciência contemporânea: surge um problema concreto; é entregue a um grupo de cientistas (especialistas) que possuem a missão de encontrar uma solução viável; o procedimento para esta solução é a repetição de testes até chegar a um método (caminho) que, a partir de sua aplicação, sempre levará à resolução do problema. A experiência é válida a partir do momento que é confirmada. Não existe um envolvimento histórico no procedimento. É isolado o problema (o objeto de pesquisa) para buscar a aplicação de um método condizente com a solução do problema. Isso é experiência na ciência moderna: "Uma experiência só é válida, na medida em que se confirma; nesse sentido, sua dignidade repousa no princípio que reza que ela pode ser reproduzida. Mas isto significa que, por sua própria essência, a experiência suspende em si mesma sua própria história e a extingue" (GADAMER, 2004a, p. 353).

Aqui temos a discussão feita pela filosofia da ciência acerca da necessidade de o cientista superar qualquer preconceito que possa vir a prejudicar o resultado de sua pesquisa. $O$ cientista deve ater-se ao procedimento metodológico previamente determinado para livrar-se de possíveis equívocos. Temos na base do procedimento o método indutivo, que colhe das experiências particulares elementos que legitimem o acesso a um conhecimento universal. Essas experiências nada mais são do que procedimentos metodológicos rígidos, observações rigorosamente calculadas. Não pode haver interferências externas ao método. Este deve ser soberano para dominar o objeto e torná-lo conhecido.

Francis Bacon (1561-1626), citado por Gadamer, é um exemplo desses objetivos da ciência. A busca pelo domínio da natureza, conhecer o verdadeiro ser da natureza a partir de seu método experimental. Evitar ações não calculadas, estando o espírito livre de determinações prévias. Este deve ser guiado metodologicamente para ter êxito no domínio da natureza. Fica clara a 
necessidade de os preconceitos não se fazerem presentes no momento da investigação, porque os preconceitos são negativos e devem ser sublimados para o objetivo da ciência. Ao colocar as pretensões metodológicas de Bacon, Gadamer nos diz:

Este método verdadeiro se caracteriza pelo fato de que nele o espírito não está meramente confiado a si mesmo. Não lhe é dado "voar" como quiser. Vê-se obrigado a ir ascendendo gradatim (passo a passo), desde o particular até o geral com o fim de adquirir uma experiência ordenada e capaz de evitar qualquer precipitação. (GADAMER, 2004b, p. 354).

Mesmo destacando a decepção 4 percebida na proposta metodológica de Bacon, Gadamer destaca a contribuição deste autor para a ciência positiva que se refere a já conhecida teoria dos ídolos, ou seja, a teoria dos preconceitos. A partir dessa teoria, busca os fundamentos de uma ciência liberta de qualquer interferência negativa na busca pelo conhecimento com validade científica. Diz Gadamer:

Sua verdadeira contribuição consiste, antes, numa investigação abrangente dos preconceitos que ocupam o espírito humano e que desviam do verdadeiro conhecimento das coisas, e com isso leva a cabo uma espécie de limpeza metodológica do espírito, o que na verdade representa mais uma disciplina do que uma metodologia. A conhecida teoria baconiana dos "preconceitos" tem um sentido de possibilitar antes de tudo um uso metodológico da razão. (Ibidem, p. 355).

Ater-se simplesmente ao aspecto teleológico da experiência na busca pelo conhecimento, é visto por Gadamer como uma falha, uma limitação da teoria baconiana. Gadamer resgata o debate de Bacon acerca da experiência a partir de uma proposta científica, para mostrar que a experiência, dentro da proposta da hermenêutica filosófica, tem o aspecto da alteridade; não pode ser vista a partir de uma proposta unilateral, simplesmente teleológica. A experiência, enquanto acontecimento e expressada na linguagem, também deve ser pensada, e de forma muito mais produtiva para a existência humana. Se limitarmos a experiência como simples repetição de procedimentos previamente determinados na busca por um conhecimento universal (absoluto), a proposta da hermenêutica filosófica, da relação de experiência enquanto alteridade, enquanto movimento dialógico aberto que valoriza a finitude e a

\footnotetext{
${ }^{4}$ Cf. GADAMER, 2004a, p. 354.
} 
historicidade existencial, estaria fadada ao esquecimento. Esse esquecimento está na base do método da ciência moderna cujos conceitos Gadamer resgata para a fundamentação de sua hermenêutica.

Pensamos ser suficiente este rápido resgate de alguns aspectos da experiência científica para podemos mostrar a experiência a partir da proposta da hermenêutica filosófica. É o resgate do aspecto positivo da experiência que foi excluída pela proposta moderna de ciência.

\section{A Experiência na Hermenêutica Filosófica}

Quando se considera a experiência na perspectiva de seu resultado, passa-se por cima do verdadeiro processo da experiência. $^{5}$

Gadamer compreende a importância da experiência pensada a partir da proposta científica; o aspecto teleológico da experiência na busca pela validade do conhecimento enquanto a experiência não é contradita por uma nova experiência. Isso faz parte do método indutivo adotado pela ciência e que resultou na possibilidade de um conhecimento prático e útil para a humanidade. Retirada todas as consequências negativas deste procedimento de domínio da natureza para obter a evolução da ciência, a metodologia teve sua contribuição. O que Gadamer vai questionar e retomar na sua hermenêutica - e nos parece fundamental para pensarmos a Educação Ambiental - é pensarmos a experiência a partir de seus elementos históricos e existenciais; a experiência para além do esquema epistemológico que visa a objetivação do conhecimento. Pensar o conteúdo original da experiência. Para isso, a definição de experiência pensada pela ciência moderna não serve para a hermenêutica filosófica e, consequentemente, para pensarmos a Educação Ambiental. A experiência não é repetição no sentido da ciência enquanto aplicação de um método. A experiência é sempre original, é sempre um novo acontecimento, não podendo nunca ser copiada, absolutizada. Ao comentar a obra de arte, acerca da repetição, nos diz: "Ao contrário, toda repetição é tão original quanto a própria obra" (GADAMER, 2004a, p. 128). A experiência do repetir é uma nova experiência. É um novo mundo de sentidos que se coloca em jogo; é a condição de temporalidade que se encontra como fator decisivo

${ }^{5}$ Cf. GADAMER, 2004a, p. 358. 
na experiência hermenêutica. Nenhuma experiência pode ser repetida por ser sempre a abertura para o novo, por ser um novo encontro com o outro, um novo acontecer do qual não temos controle.

A pretensão de repetição das experiências através da aplicação do método presente na ciência moderna é rejeitada pela hermenêutica filosófica. $E$ isto porque a experiência com consciência hermenêutica é pensada a partir da condição de abertura, de finitude, sendo, portanto, essencialmente histórica e sabendo que nada retorna, nada se fecha, acontecendo enquanto diálogo aberto. Nisto consiste a consciência das limitações do ser humano e não considerá-lo "senhor" de todos os processos sendo capaz de tudo saber. Pensar nos limites da condição humana é colocar no debate o que o lluminismo não considerou: a finitude humana que se faz presente na experiência. "Experiência é, portanto, experiência da finitude humana". (GADAMER, 2004a, p. 363). Quem tem esta consciência é chamado de experimentado. É a atitude de quem não se coloca como "senhor", mas como consciente de suas limitações, de suas inseguranças, de seus medos, de sua condição existencial.

É experimentado, no autêntico sentido da palavra, aquele que tem consciência dessa limitação, aquele que sabe que não é senhor do tempo nem do futuro. $O$ homem experimentado conhece os limites de toda previsão e a insegurança de todo o plano. Nele consuma-se o valor de verdade da experiência. (Ibidem, p. 363).

Gadamer está na trilha da crítica à pretensão absoluta de Hegel ao dizer que: "A verdadeira experiência é aquela na qual o homem se torna consciente de sua finitude. Nela, a capacidade de fazer e a autoconsciência de uma razão planificadora encontram seu limite". (GADAMER, 2004a, p. 363). Estar na condição histórica é ter a consciência de que a experiência é única; acontece originalmente por estar sob a égide da condição existencial. Estar aberto ao exercício da experiência hermenêutica é ter a consciência dos riscos, dos confrontos, dos questionamentos dos dogmas, dos preconceitos que nos constituem enquanto humanos. Do desconforto de não sabermos o que dizer, de termos que rever um posicionamento que achávamos resolvido. Nesta condição, a experiência se dá por inteira por ter essa característica negativa. A negatividade não tem um sentido pejorativo, que deva ser evitado. Pelo contrário, estar disposto a fazer a experiência é saber que, o momento de crise 
a partir dos questionamentos oriundos do outro são condição necessária para se tornar experimentado, ou seja, para o reconhecimento de sua finitude.

A experiência na hermenêutica filosófica é colocada de forma pedagógica a partir da dor e do sofrimento. Quem não passa pela negatividade da experiência não se torna consciente de sua finitude. Não estamos falando da dor no sentido físico, mas da dor enquanto amadurecimento, enquanto crescimento que só ocorre no momento em que o ser humano se abre para a experiência hermenêutica. Quem é blindado deste acontecer pedagógico não faz o exercício de confronto dos seus preconceitos, ou seja, não faz a experiência por inteiro. Fazer a experiência é parte da essência histórica do ser humano, é o caminho que o leva ao discernimento, à consciência de sua condição finita, a condição ontológica enquanto seres históricos. De acordo com Gadamer, há algo de novo nesta experiência por não ser uma experiência apenas com objetivos de instruir sobre isto ou aquilo, refere-se a experiência em seu todo 6 . Todos devem participar desta experiência como condição necessária para seu aprendizado.

\begin{abstract}
Aqui, a experiência faz parte da essência histórica do homem. Embora o objetivo limitado de uma solicitude pela educação seja o de poupar alguém de fazer certas experiências, como fazem às vezes os pais com seus filhos, a experiência, em seu conjunto, não é algo que possa ser poupado a alguém. Nesse sentido, a experiência pressupõe necessariamente que se frustrem muitas expectativas, pois somente é adquirida através disso. $O$ fato de a experiência ser eminentemente dolorosa e desagradável não corresponde a uma visão pessimista, mas provém, como se pode ver, da essência da própria experiência. Como já sabia o próprio Bacon é só através de instâncias negativas que se chega a uma nova experiência. Toda experiência digna desse nome teve que se livrar de algum tipo de expectativa. Assim, o ser histórico do homem contém, como um momento essencial, uma negação fundamental que aparece na relação essencial entre experiência e discernimento. (GADAMER, 2004a, p. 361-362).
\end{abstract}

A instância negativa da experiência destacada na citação acima revela 0 caráter pedagógico; revela a finitude do ser humano na sua condição de ser jogado no mundo; da relação com o todo, da relação com o outro enquanto sujeito hermenêutico, ou seja, enquanto sujeito que interpreta a partir da experiência ontológica que acontece no diálogo aberto. Esta relação dialógicodialética é fundamental para que a experiência hermenêutica revele a sua

${ }^{6}$ Cf. GADAMER, 2004a, p. 361. 
negatividade e nos mostre o que até então não tínhamos atentado. Já tínhamos tido o contato com o objeto (outro), mas não o tínhamos visto corretamente; percebemos algo de novo, que não confirma o que achávamos ser correto. Desestabiliza nossas compreensões prévias ao não se confirmarem.

A condição de inacabamento revelada na finitude de seres em constante condição de aprendizado, de compreensão a partir da situação existencial da experiência ontológica, demonstra nossos limites diferenciando-nos do homem moderno que está sob a égide da razão. A experiência humana é a experiência de sua finitude e é nesta que evoluímos enquanto compreensão e consciência de nossas limitações. É nela que percebemos o sofrimento e a dor como experiências pedagógicas, reveladoras de nosso ser ontológico.

O homem deve aprender pelo sofrer não é isto ou aquilo. Ele precisa discernir os limites do ser humano, alcançar o discernimento de que as barreiras que nos separam do divino não podem ser superadas. No fundo, trata-se de um conhecimento religioso - aquele conhecimento a partir donde nasce a tragédia grega ${ }^{7}$. (GADAMER, 2004a, p. 362-363).

Gadamer destaca, ao problematizar a experiência negativa, o duplo sentido da experiência: "as experiências que correspondem às nossas expectativas e as confirmam; de outro, a experiência que se 'faz'” (GADAMER, 2004a, p. 359). A segunda, a que se faz, é sempre negativa, ou seja, não confirma o que já sabíamos, mas revela algo de novo, derruba nossas expectativas e nos desestabiliza tornando-se produtiva. De acordo com a hermenêutica filosófica, a experiência tem que ter este caráter negativo para tornar-se produtiva, para transformar os sujeitos envolvidos. Ter contato com o outro fazendo o movimento dialógico proporciona um saber amplo; nossos preconceitos são questionados a partir da nova experiência e assim propicia novos conhecimentos que até então eram desconhecidos ou que tiveram que ser revistos por falhas na interpretação. "Quando fazemos a experiência com um objeto significa que até então não havíamos visto corretamente as coisas e

\footnotetext{
7 Ao comentar essa passagem, Almeida nos diz: "Gadamer considera a dor e o sofrimento grandes 'pedagogos' da experiência ontológica da finitude. Padecendo, aprendemos os próprios limites de ser humano. Por isso ele reconhece o profundo sentimento religiosos que se manifesta na origem da tragédia grega." (ALMEIDA, 2002, p. 284).
} 
que só agora nos damos conta de como realmente são" (Ibidem, p. 359). É algo novo que se apresenta num novo contato ou num primeiro contato. Façamos um exercício: ao relermos um livro ou um artigo; ao assistirmos um filme; ao retomarmos um diálogo com um colega. Neste movimento, percebemos coisas que no contato anterior não havíamos percebido. Este movimento é próprio da experiência que se dá enquanto acontecer de nossa finitude. De uma experiência negativa conseguimos a ampliação de nossa compreensão, de nossos preconceitos. Como nos coloca Hermann (2002, p. 36) são as visões prévias (Vorsicht), posição prévia (Vorhabe) as concepções prévias (Vorgriff) já presentes na filosofia de Martin Heidegger (1889-1976). De acordo com a nossa interpretação, estes conceitos são absorvidos pela hermenêutica gadameriana.

A experiência que objetiva apenas a confirmação de resultados, como ocorre nas ciências particulares, furta o verdadeiro sentido da experiência com vistas à aquisição de novos conhecimentos. Como destacamos na epígrafe, quando se considera a experiência na perspectiva de seu resultado, passa-se por cima do verdadeiro processo da experiência. Qual seria este verdadeiro processo da experiência? É a experiência que se estrutura no movimento dialógico-dialético. Ao entrarmos em contato com o outro (um texto, uma pessoa, uma obra de arte etc.) não sabemos previamente o resultado desse movimento. A experiência não está estruturada metodologicamente para chegarmos a determinado lugar.

Esse contato que nos proporciona uma experiência negativa se torna produtiva justamente por mostrarmo-nos o que antes não tínhamos compreendido, não tínhamos percebido. Esta é a importância da experiência hermenêutica: desestabilizar-nos, num primeiro momento, para proporcionar um novo conhecimento; porém, este não é absoluto, mas um acontecimento que se encontra sempre aberto a novos questionamentos. "A negação, em virtude da qual a experiência chega a esse resultado, é uma negação determinada. A essa forma da experiência damos o nome de dialética." (lbidem, p. 359).

\section{Considerações Finais}


A hermenêutica filosófica como fundamento para Educação Ambiental quer questionar as teorias que buscam a congenialidade dos fatos, a objetividade científica do conhecimento, a exclusão da possibilidade de problematização e diálogo. As individualidades dialogam a partir das culturas, ou seja, não existe sujeito, não existe individualidade se não for pensada na sua presença, na sua inserção numa determinada cultura. Numa tradição. E este eu individual se dá no diálogo com o tu, com o outro. Esta relação é de fundamental importância ao pensarmos a hermenêutica filosófica: esta se fundamenta no diálogo entre dois mundos de sentidos superando a relação pura e simplesmente exploratória, científica da hermenêutica clássica, que pretende a compreensão idealista fundamentada na metafísica absoluta, visando à objetividade da investigação.

Como sabemos, não existe indivíduo pensado fora de uma cultura, de uma tradição à qual ele pertence. Alguém poderia fazer o seguinte questionamento: a dificuldade ou quase incapacidade que hoje presenciamos para o encontro, enquanto diálogo provocado pelo advento das redes sociais, pode ser colocado como uma manifestação cultural? Esta situação traz consequências para a Educação? O que podemos afirmar é que hoje pensamos e nos movemos atingidos por este momento histórico, mesmo não tendo a capacidade de interpretarmos com clareza este momento conturbado que pode ser uma das causas da crise ambiental ao propagar cada vez mais as posturas individualistas e consumistas, base do sistema econômico do qual fazemos parte. Existe um sistema que prega o individualismo como modo de comportamento. Isso é fato! Em consequência desse comportamento, temos a dificuldade para o diálogo. Não é uma dificuldade de comunicação, ou melhor, dificuldade de repasse de informações, dado que as informações nunca foram tão eficientes como nos dias atuais. Percebemos a dificuldade das pessoas em dialogarem no sentido de se encontrarem, de reservarem um tempo de suas vidas para este exercício. Essa é uma nova cultura que se instaurou e tem guiado os comportamentos humanos hodiernos.

Tendo presente os problemas causados pela proposta metodológica da modernidade, é que Gadamer reflete acerca das consequências do avanço desenfreado da ciência moderna, vendo a necessidade de pensarmos uma proposta que não se baseie pura e simplesmente no método científico que visa 
a objetivação absoluta e a exclusão do diálogo enquanto proposta metodológica. Temos a responsabilidade ética de problematizarmos e debatermos os problemas provocados pela humanidade. Isto só se dará admitindo a nossa condição de seres finitos, pertencentes a uma condição existencial, aptos para o diálogo enquanto metodologia pedagógica que respeita e debate com as diferenças. Temos que assumir, enquanto seres humanos, a responsabilidade ética dos saberes produzidos. A modernidade, com sua postura instrumental, excluiu esta necessidade.

$\mathrm{Na}$ esteira do propósito que aqui procuramos apresentar como fundamento para a Educação Ambiental se encontra a necessidade de retomarmos um debate esquecido pela proposta de um sujeito cognoscitivo presente na modernidade; o esquecimento pelo debate sobre o Ser como base de nossa condição de finitude desenvolvido por Heidegger, a continuidade desse debate feito por Gadamer com o desvelamento da experiência ontológica presente pedagogicamente na maiêutica socrática e na dialética platônica, ambos indicando o diálogo como caminho para a verdade ${ }^{8}$. Como adiantamos anteriormente, Gadamer retira a pretensão de verdade presa à presunção de certeza absoluta. Na sua concepção, isto se torna contraditório, em vista da condição de finitude do ser humano. Se trilharmos o caminho de um sujeito cognoscitivo, capaz de alcançar a verdade absoluta e o domínio da natureza enquanto objeto (projeto este presente na proposta moderna), tornase descartada a necessidade de avaliar suas ações a partir da dimensão ética, do diálogo crítico e problematizador, assumindo suas responsabilidades. Gadamer introduz o diálogo como movimento pedagógico, como metodologia hermenêutica para que a interpretação se dê no movimento dialético-dialógico. Com isso, o diálogo, tal como o interpretamos, proporciona a necessidade da problematização e, consequentemente, da reflexão ética do agir humano. Fora deste movimento, resta somente a técnica, a pesquisa enquanto cegueira instrumental presente na Razão lluminista. Seguir esse caminho é ficarmos preso à estrutura tecnicista causadora $a b$ ovo da crise ambiental, sem qualquer responsabilidade com o futuro do meio ambiente. Por isso a necessidade da ética enquanto problematizadora das ações humanas.

\footnotetext{
8 Cf. GOERGEN, 2010, p. 17.
} 
(...) a verdade, despojada de sua presunção de certeza absoluta, constitui-se num processo infinito e sempre provisório em que confluem saber e ética em uma relação da qual tanto se ressente a natureza dominadora da razão instrumental. A dimensão ética emerge do processo dialético-dialógico no qual os participantes aprendem a assumir responsabilidade sobre seu próprio agir. Com isso, desvela-se a trágica relação apontada por Adorno e Horkheime entre a cegueira instrumental e a consequente cegueira ética inscritas na razão iluminista. (GOERGEN, 2010, p. 17).

A proposta de uma hermenêutica filosófica como fundamento para a Educação Ambiental não é superar o abismo histórico-temporal existente entre os mundos de sentido na busca pela desmitologização das mensagens, ou seja, não quer excluir nossos problemas sociais dos quais nos constituímos. Se fizermos isso caímos nas armadilhas do "canto da sereia" lluminista, já denunciado por Adorno (1903-1969) e Horkheime (1895-1973). Por isso, a saída encontrada por Gadamer é a hermenêutica enquanto diálogo. O outro não é visto como algo a ser dominado, a ser superado, mas deve ser visto como uma experiência do encontro com uma nova realidade, com um novo mundo de sentido que auxilia na compreensão e na interpretação de novas realidades. A experiência com o outro se dá numa relação dialógica cujo movimento não se tem controle e não se pretende ter controle. A proposta não é ir ao encontro com o objetivo de simples observação e decodificação com vias utilitaristas e pragmatistas; a experiência hermenêutica escapa ao nosso controle por nos entregarmos ao movimento dialógico, em que o contato com o outro nos provoca, nos desestabiliza fazendo com que nossas convicções possam ser revistas.

O encontro com o outro é que enobrece o movimento dialógico. Essa experiência dialética que nos marca, nos transforma, nos atinge ao ouvirmos, ao sermos questionados e termos que rever nossos argumentos e refazermos a forma de pensar. $O$ fato de ouvirmos o outro e deixarmos essa experiência nos marcar é que faz a educação ser transformadora. Devemos ter uma relação de outridade vendo no outro a possibilidade de fazer a experiência hermenêutica. Não podemos ver o outro um oponente ou uma ameaça aos nossos argumentos. Isso seria desastroso para com os objetivos de uma Educação que vê no diálogo a base de uma Educação transformadora. O outro é a condição necessária para a experiência hermenêutica e é onde a Educação 
acontece, onde somos marcados pelo diferente, onde a reflexão ética acontece.

Um diálogo é, para nós, aquilo que deixou uma marca. O que perfaz um verdadeiro diálogo não é termos experimentado algo de novo, mas termos encontrado no outro algo que ainda não havíamos encontrado em nossa própria experiência de mundo. [...] O diálogo possui uma força transformadora. Onde um diálogo teve êxito ficou algo para nós e em nós que nos transformou. (GADAMER, 2004b, p. 211).

$\mathrm{Na}$ perspectiva que se apresenta à Educação sob a óptica da hermenêutica de Gadamer, a postura dialógica adotada propõe ver o outro como um parceiro para o desenvolvimento do conhecimento, para o debate dos conceitos, para a problematização das questões elencadas. O diálogo não pode ser visto como um momento de disputa ou concorrência dos argumentos utilizados (como ocorre num debate jurídico), mas um momento em que todos os participantes do diálogo possam se enriquecer com as ideias, com os conceitos utilizados. É o que Gadamer chama de "ampliação dos horizontes de sentido" que se dá a partir da fusão dos horizontes no movimento dialógico. Os preconceitos, oriundos de nossa condição existencial são vistos de forma positiva pela hermenêutica filosófica, são colocados como um dos pilares da Educação hermenêutica. Dialogamos a partir das nossas concepções prévias que guiam nosso raciocínio, estes são frutos de nosso ser e estar no mundo que orientam nossas interpretações e que se apresentam no jogo dialógico. Buscar a superação ou a exclusão dos preconceitos é tornar estéril a hermenêutica enquanto Educação, por retirar a possibilidade dos participantes confrontarem os seus próprios preconceitos e vendo neles o horizonte reflexivo. Ao permitir esse movimento dialógico, quem se apresenta para o diálogo é o indivíduo concreto que coloca à baila suas preocupações, suas angústias e não um indivíduo genérico, que recebe conteúdos que estão fora das suas preocupações existenciais. Quem deve estar sendo questionado é o participante por ser no movimento de pergunta-resposta presente no diálogo que o conhecimento se realiza. Se não houver questionamento, crise, angústias em relação ao que é debatido, não haverá a emergência do conhecimento, não haverá a geração da reflexão ética.

(...) a necessidade de levar a sério a pessoa concreta (com seus preconceitos, suas perguntas específicas, suas biografias e experiências de socialização), mas também de ter presente a história e 
a linguagem como horizontes desde sempre dados, que condicionam 0 "vir ao encontro" do outro nem sempre previsível. Sem dúvidas é no diálogo que vivemos a irritação causada pela pergunta do outro e o risco de ver nossas supostas certezas postas em xeque. (FLICKINGER, 2010, p. 6).

Ao destacarmos o diálogo enquanto fundamento metodológico para a Educação, enfatizamos ao mesmo tempo a importância do diálogo para os fundamentos da Educação Ambiental consubstancializada por seus protagonistas (pesquisadores, professores, estudantes, movimentos sociais etc.) a fim de levarem em conta a necessidade de que os seus preconceitos serem colocados no "jogo dialógico" para podermos amadurecer cada vez mais as teorias que buscam compreender a crise ambiental. Se ficarmos presos a um único caminho possível, tornamo-nos dogmáticos, o que impede o debate crítico. Se tivermos a abertura para o debate, poderemos rever nossas compreensões, escutar as compreensões dos outros e, juntos, formularmos possíveis soluções para uma reflexão madura acerca da problemática em questão. Acreditamos ser o diálogo hermenêutico um movimento possível para ouvirmos as múltiplas vozes que se ocupam/preocupam com a Educação Ambiental e, assim, não esgotarmos a Educação em uma mera "transmissão" de conhecimento.

\section{Referências}

ALMEIDA, Custódio L.S. Hermenêutica e Dialética: dos estudos platônicos ao encontro com Hegel. Porto Alegre: Edipuc, 2002.

ANDRADE, Carlos Drummond de. Mãos dadas. In: Sentido do Mundo. São Paulo: Companhia da Letras, 2012.

FLICKINGER, Hans-Georg. A caminho de uma pedagogia hermenêutica. Campinas - SP: Autores Associados, 2010.

GADAMER, Hans-Georg. Verdade e Método I: Traços fundamentais de uma hermenêutica filosófica. Trad. Flávio Paulo Meurer. $6^{\circ}$ ed. Petrópolis: Vozes, 2004a.

GADAMER, Hans-Georg.Verdade e Método II: complementos e índice. Trad. Enio Paulo Giachini. Petrópolis, RJ: Vozes, 2004b.

GOERGEN, Pedro. Prefácio. In. FLICKINGER, Hans-Georg. A caminho de uma pedagogia hermenêutica. Campinas: Autores Associados, 2010. 
GRÜN, Mauro. Em busca de uma dimensão ética da educação ambiental. Campinas, SP: Papirus, 2007.

HERMANN, Nadja. Hermenêutica e Educação. Rio de Janeiro: DP\&A, 2002. 